\title{
Самаева А.M. \\ Дискурсивное описание эмоционального концепта «страх»/«fear» (на материале пословиц и поговорок)
}

Калмыцкий государственный университет (Россия, Элиста)

doi: $10.18411 / \mathrm{j}-06-2021-136$

\section{Аннотация}

В данной статье приводятся и анализируются конкретные примеры пословиц и поговорок, в которых можно обнаружить описание эмоционального концепта «страх»/《fear» с точки зрения английской и русской лингвокультур. Более детальное рассмотрение этих примеров позволит выявить сходства и различия в отношении народов к страху и его проявлениям.

Ключевые слова: эмоция, концепт, страх, лингвокультура, пословицы, поговорки.

\section{Abstract}

In this article are given and analyzed some specific examples of proverbs and sayings, in which one can discover the description of emotional concept «fear» from the English and Russian linguistic cultures' point of view. More detailed consideration will allow us to identify similarities and differences of the nations' attitude to fear and expressions of it.

Keywords: emotion, concept, fear, linguistic culture, proverbs, sayings.

Пословицы и поговорки создавались народом на протяжении тысячелетий. Их исследование (в равной степени, как и исследование фразеологизмов) несет определенную ценность для исследования концепта с точки зрения его диахронического становления.

Именно в пословично-поговорочном фонде языка накапливается информация и ясно прослеживается специфика представления и осознания страха.

Нельзя не заметить, что при кажущейся многоаспектности и обширности исследований в этой сфере, вопрос о разграничении терминологических статусов пословиц и поговорок до сегодняшнего дня остается открытым.

Многие исследователи разделяют термины «пословица» и «поговорка», основываясь на принципе синтаксической завершенности. К числу же характеристик, объединяющих пословицы и поговорки и позволяющих обобщить их одним термином «паремия», относятся такие, как источник происхождения (в основном они являются результатом народного творчества), устойчивость воспроизведения в речи, отражение и обобщение жизненных закономерностей, назидательный и рекомендательный характер.

В английской и русской лингвокультурах имеются общие тематические группы пословиц и поговорок. Тем не менее, их нельзя назвать эквивалентами, потому как, хоть они и схожи в идейном смысле, но расходятся по лексико-грамматическому оформлению.

Так, и английский, и русский языки имеют в своем лингвоарсенале пословицы, которые объединены общей идеей: «пережив однажды ситуацию страха, человек начинает бояться всего, даже самого незначительного» [3].

В русском языке эта идея находит реализацию через зооморфизмы, распространенные в пословицах и поговорках, например, «пуганая ворона куста боится».

В английском языке можно найти: «A burnt child dreads the fire».

Помимо прочего, английская пословица «Threatened folks live the longest: they take precautions» является свидетельством тому, что для англичанина свойственно 
принимать меры предосторожности, чтобы впредь избежать опасной ситуации. В психологии это называется адаптивная функция страха. [1]

Осмысление страха через смерть также находит свое воплощение в пословицах. Пословицы на эту тематику обнаруживаются в обоих языках, но любопытно, что отношение к смерти как причине возникновения страха разное для сопоставляемых культур.

Для сознания русскоязычного человека, смерть является неизбежным фактом. Она рассматривается как переход на другой уровень существования, а страх смерти как естественное чувство человека: «Жив смерти боится». Смерть не рассматривается как высшая форма страха: «Страх сильнее смерти».

Русское сознание не отстраняется от смерти, оно примиряется с ней, превращает ее в факт жизни. У русских отношение к жизни сводится к тому, что ко всему надо относиться по-доброму, даже к смерти, принимая ее.[2]

Англичане в своих пословицах хотя и признают страх смерти самым интенсивным («The fear of death is more to be dreaded, than the death itself»), но при этом также и осуждают его («If you fear death, you already dead»).

Рассматриваемые культуры отдельно выделяют такую характерную черту эмоционального концепта (далее - ЭК) «страх», как управление поступками людей (следует отличать от использования страха как средства манипулирования).

Английское языковое сознание различает:

a) позитивное воздействие страха, которое подчеркивает поучающую (адаптивную) функцию страха: «A good scare is worth more to a man than good advice», «Fear is the beginning of wisdom»;

б) негативное влияние на поступки человека: «Our fears do make us traitors», «A slave to fear creates the hell on earth»;

в) нейтральное воздействие страха: «Men who are afraid are in love with fear», «Those who came were not afraid: those who were afraid didn't come».

В нашем языке страх рассматривается в большинстве своем качестве нейтрального регулятора при оценке поступков людей: «На всяку беду страху не напасешься», «Не стоит тратить свою жизнь на страх».

Данные пословицы носят скорее прескриптивный, философский характер. Они отражают размышления человека о значимости страха и месте в его жизни. Также это немного связано с пониманием смерти.

И в английском, и в русском языках подчеркивается, что неискушенный, наивный человек не испытывает страха. В английской пословице ставится акцент на том, что страх может быть не врожденной, а приобретенной эмоцией: «Newborn calves don't fear tiger».

В русском языке отмечается, что страх является эмоцией осознанной. Страх испытывает тот, кому есть, что терять: «Глаза страшатся, а руки делают», «Дело мастера боится» и др.

Говоря о межкультурных различиях, важно отметить, что они имеют свойство сказываться и на качественной наполняемости того или иного пословичного вербального пространства эмоционального концепта «страх»/«fear».

Как в английском, так и в русском языках страх приобретает очертания через концепт «храбрость/мужество».

В английском языке мужество поощряется, и также подчеркивается, что в основе храбрости лежит именно страх: «Courage is fear that has said its prayers», "One must have courage even to fear».

Русский язык располагает богатым разнообразием представлений ЭК «страх» через храбрость. В частности, отсутствие страха вознаграждается: «Смелого удача догоняет», «Смелый там найдет, где робкий потеряет». 
Наиболее ярким признаком храбрости, который является релевантным для русского языкового сознания, предстает своевременность.

Тем не менее, в иллюстративных примерах наблюдается ирония по отношению к храбрости, появляющейся не в минуты угрозы жизни или здоровью, а в безопасном месте: «Хорошо медведя в окно дразнить!», «Все собаки сильны у себя во дворе».

Тут же выделяется группа пословиц, описывающих обманчивую, напускную храбрость. Внешность может противоречить поступкам и образу жизни человека: «Сердце соколье, а смелость воронья», «Повадки волчьи, а душа заячья».

Вдобавок, в сравниваемых языках были обнаружены пословицы, характеризующие исследуемый концепт через пограничный концепт «трусость».

В английском языке трусость осуждается: «It is folly to die through fear of dying». В русском языке она скорее просто не поощяется (по данному признаку трусость противопоставляется храбрости): «Несмелый всегда позади».

В английском языке дается качественная характеристика трусу: «Cowards are cruel». Особенностью русского языкового сознания можно обозначить оправдание трусости: «Бег не честен, да здоров».

Англичане более категорично высказывают свое отрицательное отношение, осуждение недостойного, по их мнению, поведения.

Отечественная лингвокультура оправдывает такую черту характера более «мягко», и даже в некоторой степени снисходительно относится к этому.

В английских пословицах и поговорках выражен семантический признак «продолжительность». Страх может быть:

- продолжительным: «Endless are the torments of him who fears himself»;

- преждевременным: «Let's fear no storm, before we feel the shower»;

- указывается возможное время переживания страха: «Don't be afraid of tomorrow, look what could happen today».

В пословично-поговорочном фонде английского языка выделяется такой признак ЭК «fear», как способность использования его в целях манипуляции человеком: «Terror is great temptation», «He threatens who is afraid».

При этом стоит упомянуть, что в русском языке в пословицах и поговорках этот семантический признак не актуализируется.

Невзирая на непреодолимость и неотвратимость страха, англоязычный народ продолжает надеяться на избавление от него: «Let the fearful be allowed to hope», «Не has no hope who never had fear».

Таким образом, английские пословицы учат стойко и терпеливо переносить страх, жить с надеждой на возможное избавление. Русские пословицы уверяют, что только активные действия помогут преодолеть и побороть страх.

Итак, в заключение можно сказать, что и сходства, и различия в целом в одинаковой степени имеют место быть в предметно-образном содержании пословиц и поговорок, которые отражают эмоциональный концепт «страх» в обеих лингвокультурах.

$$
\text { *** }
$$

1. Изард К. Психология эмоций. - СПб.: Питер, 2000. - 450 с.

2. Попова З.Д., Стернин И.А. Очерки по когнитивной лингвистике. - Воронеж: Издательство «Истоки», 2001. - 141-142 с.

3. Семененко Н.Н. Лингвокультурологическое описание структуры и семантики паремий: Автореф. дис. ...канд. филол. наук. - Белгород, 2002. - 24 с.

4. https://sbornik-mudrosti.ru/poslovicy-i-pogovorki-pro-strax/

5. http://www.special-dictionary.com/proverbs/keywords/fear/4.htm 